\title{
Long-term outcome of bioresorbable vascular scaffolds for the treatment of coronary artery disease: a meta-analysis of RCTs
}

Alberto Polimeni ${ }^{1,2,3} \mathbb{D}$, Remzi Anadol ${ }^{1,2}$, Thomas Münzel ${ }^{1,2}$, Ciro Indolfi, ${ }^{3,4}$, Salvatore De Rosa ${ }^{3+}$ and Tommaso Gori ${ }^{1,2^{*}+}$

\begin{abstract}
Background: Coronary bioresorbable scaffolds (BRS) were developed to overcome the limitations of standard metallic stents, especially to address late events after percutaneous coronary interventions. The aim of this meta-analysis was to evaluate the efficacy and safety of BRS, compared with Everolimus-eluting stents (EES), using the data available from randomized trials, with a focus on long-term outcomes.

Methods: Published randomized trials comparing BRS to EES for the treatment of coronary artery disease were searched for within PubMed, Cochrane Library and Scopus electronic databases up to April 4th 2017. The summary measure used was odds ratio (OR) with 95\% confidence intervals.

Results: A total of 5 studies were eligible, including 5219 patients. At 2 years, BRS was associated with higher rates of target lesion failure (9.4\% vs 7.2\%; $\mathrm{OR}=1.33 ; 95 \% \mathrm{Cl} 1.07$ to $1.63 ; p=0.008)$ and device thrombosis $(2.3 \%$ vs $0.7 \%$; $\mathrm{OR}=3.22 ; 95 \% \mathrm{Cl} 1.86$ to $5.57 ; p<0.0001$ ) compared with EES. The incidence of both early (within 30 days after implantation, $1.1 \%$ vs $0.5 \%$, OR $1.97,95 \% \mathrm{Cl} 1.02$ to $3.81 ; p=0.05$ ) and very-late device thrombosis ( $>1$ year, $0.6 \%$ vs 0 . $1 \%$, OR $4.03,95 \% \mathrm{Cl} 1.37$ to $11.82 ; p=0.01$ ) was higher with BRS compared with EES.
\end{abstract}

Conclusions: BRS may be associated with worse two-years clinical outcomes compared with EES in patients with coronary artery disease.

Keywords: Stent thrombosis, Target lesion failure, Bioresorbable vascular scaffold

\section{Background}

The introduction of coronary stents has revolutionized interventional cardiology. However, despite significant improvement over the years, traditional metallic stents have some intrinsic limitations. In fact, their permanent structure hinders surgical myocardial revascularization, physiological vessel remodeling and exposes patients to the risk of stent thrombosis for an indefinite time. Coronary bioresorbable scaffolds (BRS) were developed to overcome some of these limitations of standard

\footnotetext{
*Correspondence: tommaso.gori@unimedizin-mainz.de

${ }^{\dagger}$ Equal contributors

${ }^{1}$ Zentrum für Kardiologie, University Hospital Mainz, Mainz, Germany

${ }^{2}$ German Center for Cardiac and Vascular Research (DZHK), Standort

Rhein-Main, Mainz, Germany

Full list of author information is available at the end of the article
}

metallic stents, especially to address late events after percutaneous coronary interventions (PCI) [1]. BRS have been introduced in the last years as a novel promising approach to treat coronary stenosis by providing transient vessel support with drug delivery capability without the long-term limitations associated with vessel caging [2]. This technology has the potential to overcome many of the safety concerns associated with drug-eluting stents, with possible clinical benefits [3]. Although initial reports from single-arm studies in highly selected patients with simple coronary lesions were reassuring [4-6], recent data from "real-life" registries and randomized controlled trials reported that the rates of scaffold-related are not negligible, also at long-term [7-9]. 
The aim of this meta-analysis was to evaluate the efficacy and safety of BRS, compared with Everolimuseluting stents (EES), using the data available from randomized trials, with a focus on long-term outcomes.

\section{Methods}

\section{Search strategy and study selection}

Published randomized trials comparing BRS to EES for the treatment of coronary artery disease were searched for within PubMed, Cochrane Library, Scopus electronic databases and scientific sessions abstracts, and relevant websites (www.clinicaltrialresults.org, www.escardio.org, www.tctmd.com) up to April 4th 2017. We checked the reference lists from all eligible studies to identify additional citations. The following keywords and the corresponding MeSH terms were used for search: "bioresorbable vascular scaffold", "everolimus-eluting stent", "coronary artery disease", "randomized controlled trial". Time of publication and language were not limiting criteria for our analysis. All reports including the search terms were independently screened by two investigators for relevance and eligibility (AP, RA). Additionally, references from relevant articles were also scanned for eligible studies. The authors discussed their evaluation and any disagreement was resolved through discussion and re-reading. All selected trials were thoroughly checked and classified by author's institution in order to avoid any effect from duplicity of data.

Studies were considered eligible if the following statements were applying: a) they involved a study population with coronary artery disease; b) multicenter randomized controlled trials c) they compared BRS versus EES; d) follow-up length of 2 years; e) they reported outcome data: target lesion failure (TLF), device thrombosis (DvT), cardiac death, target-vessel myocardial infarction (TVMI), ischemia-driven target lesion revascularization (ID-TLR); f) minimum of 100 patients treated with BRS. Exclusion criteria were (just one was sufficient for study exclusion): duplicate publication, pre-specified endpoint, measure not specified. Studies reporting only lesion-based analyses were excluded from the present work.

\section{Data abstraction, validity assessment and analysis}

Baseline characteristics as well as numbers of events were extracted from the single studies, through carefully scanning of the full article by two independent reviewers (AP, SDR). Divergences were resolved by consensus. In particular, the following data were abstracted: year of publication, location, number of study patients, study design, clinical outcome data, baseline patients' characteristics. Selection and data abstraction was performed according to the PRISMA statement [10]. The primary analysis was based on the composite endpoint of TLF (Cardiac death, TVMI, ID-TLR). Furthermore, meta-analysis results of single endpoints are also provided (Probable/definite DvT; early/late/very late DvT; ischemia-driven target vessel revascularization; target vessel myocardial infarction; cardiac death). Since some of the RCTs pool definite and probable DvT, we evaluated only the incidence of the composite endpoint "definite/probable DvT".

\section{Statistical analysis}

The summary measure used was the Odds Ratio (OR) with $95 \%$ confidence interval. The random-effects model was used, as previously described, to combine the collected values [11]. This model calculates a weighted average of the relative risks by incorporating within-study and between-study variations. Heterogeneity was assessed by means of the Cochrane $\mathrm{Q}$ test using a chi-squared function, with $p$ values $<0.10$ considered significant for heterogeneity, as previously described [12]. Additionally, $\mathrm{I}^{2}$ values were calculated for estimation of variation in weighted mean differences among studies attributable to heterogeneity. Any $\mathrm{I}^{2}$ value $>20 \%$ was considered significant. Small study effects were evaluated through graphical inspection of funnel plots, as already previously described [13]. Forest plots were used to graphically display the results of the meta-analysis, as already previously described [14]. Briefly, the measure of effect (OR) for each single study included (represented by a square) is plotted, together with confidence intervals, represented by horizontal lines. The area of each square is proportional to the study's weight in the meta-analysis. The overall measure of effect is reported on the bottom line of the plot as a diamond, whose lateral ends indicate the confidence interval for the summary effect. Analyses were performed by means of RevMan 5.3.

\section{Results}

\section{Search results}

Our search retrieved a total of 590 entries, which were reduced to 30 studies after an initial pre-screening. Fifteen studies were then excluded for one of the following reasons: a) they were not related to our research question b) they weren't original articles. In the assessment of eligibility further 10 studies were excluded. Finally, a total of 5 studies were available for the analysis including 5219 patients [15-19]. The study selection procedure is reported in detail in Fig. 1.

\section{Study characteristics}

Only multicenter, randomized, trials were included in the present meta-analysis. Table 1 summarizes the most relevant characteristics of the selected studies. Not surprisingly, quality assessment revealed a high study quality (Additional file 1: Figure S1). Moreover, endpoint assessment and data analysis was blinded in all included studies. 


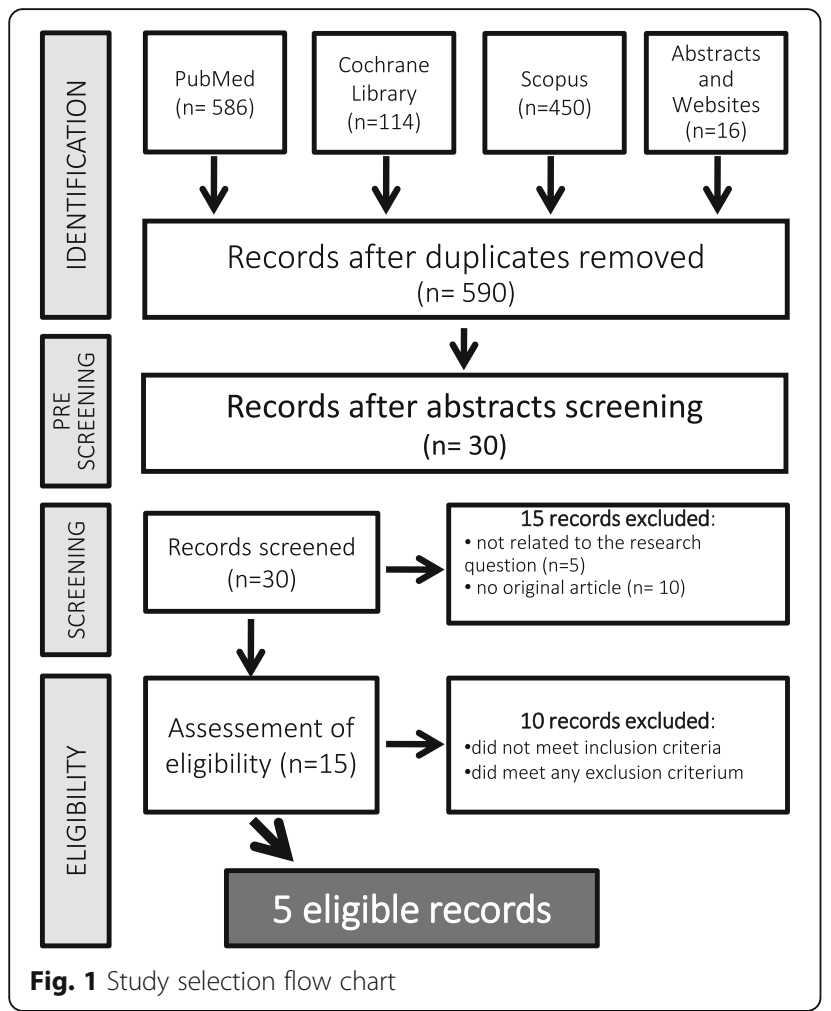

Across the studies, patients were predominantly male and approximately one fourth of patients had diabetes mellitus. Although prevalence of single cardiovascular risk factors was not equal among the studies, treatment arms were generally well balanced. Dual antiplatelet therapy was used at least 1 year in all the studies.
More details on patients' characteristics are provided in Table 2.

\section{Meta-analysis results}

At 2 years, BRS was associated with higher rates of TLF compared with EES (9.4\% vs $7.2 \%$; OR $=1.33$; $95 \%$ CI 1.07 to $1.63 ; p=0.008, \mathrm{I}^{2}=0 \%$ ) (Fig. $2 \mathrm{a}$ ). This result was driven by a major incidence of TLR $(5.1 \%$ vs $4.0 \%$; $\mathrm{OR}=1.32 ; 95 \%$ CI 1.01 to $1.74 ; p=0.05, \mathrm{I}^{2}=0 \%$ ) (Fig. $2 \mathrm{~b}$ ) and TV-MI (5.7\% vs $3.3 \%$; OR $=1.66$; $95 \%$ CI 1.25 to 2.21 ; $p=0.0005, \mathrm{I}^{2}=0 \%$ )(Fig. 3a) in BRS group compared with EES. No difference in Cardiac death $(1.2 \%$ vs $1.4 \%$; $\mathrm{OR}=0.94 ; 95 \%$ CI 0.56 to $1.57 ; p=0.80, \mathrm{I}^{2}=0 \%$ ) was observed between both groups (Fig. 3b).

BRS was associated with higher rates of DvT compared with EES (2.3\% vs $0.7 \%$; OR $=3.22$; $95 \%$ CI 1.86 to 5.57 ; $p<0.0001, \mathrm{I}^{2}=0$ ) (Fig. 4). Interestingly, the incidence of both early (within 30 days after implantation, $1.1 \%$ vs $0.5 \%$, OR $1.97,95 \%$ CI 1.02 to $3.81 ; p=0.05$ ) and very late DvT ( $>1$ year, $0.6 \%$ vs $0.1 \%$, OR $4.03,95 \%$ CI 1.37 to 11.82; $p=0.01)$ ) was higher with BRS compared with EES (Fig. 5a, c), with the majority of events occurring within 30 days $(n=44)$. Conversely, although numerically higher with BRS compared to EES, the incidence of late DvT (30 days to 1 year) was not statistically different between devices ( $0.5 \%$ vs $0.1 \%$, OR $3.44 \%$, $95 \%$ CI 0.62 to $19.12 ; p=0.16$ ) (Fig. $5 \mathrm{~b}$ ).

These results were unchanged when fixed effects model was used. There was no evidence of publication bias by visual inspection of Funnel plots and by Egger's test (Additional file 2: Figure S2).

Table 1 Characteristics and Endpoint definitions of included randomized trials

\begin{tabular}{|c|c|c|c|c|c|c|c|c|c|}
\hline Study & Year & Location & Number & Study design & Primary endpoint & Definition of TLF & Definition of ST & Follow up (months) & Lost to FU (\%) \\
\hline$\overline{A I D A}$ & 2017 & Multicenter & 1845 & RCT & TVF & $\begin{array}{l}\text { Cardiac } \\
\text { death, } \\
\text { TVMI, } \\
\text { ID-TLR }\end{array}$ & ARC & 24 & 2.8 \\
\hline ABSORB III & 2017 & Multicenter & 2008 & RCT & TLF & $\begin{array}{l}\text { Cardiac } \\
\text { death, } \\
\text { TVMI, } \\
\text { ID-TLR }\end{array}$ & ARC & 24 & 2.1 \\
\hline $\begin{array}{l}\text { ABSORB } \\
\text { China }\end{array}$ & 2016 & Multicenter & 480 & RCT & IS-LL & $\begin{array}{l}\text { Cardiac } \\
\text { death, } \\
\text { TVMI, } \\
\text { ID-TLR }\end{array}$ & ARC & 24 & 3.7 \\
\hline ABSORB ॥ & 2016 & Multicenter & 501 & $\mathrm{RCT}$ & Vasomotion, MLD & $\begin{array}{l}\text { Cardiac } \\
\text { death, } \\
\text { TVMI, } \\
\text { ID-TLR }\end{array}$ & ARC & 24 & 4.2 \\
\hline $\begin{array}{l}\text { ABSORB } \\
\text { Japan }\end{array}$ & 2016 & Multicenter & 400 & RCT & TLF & $\begin{array}{l}\text { Cardiac } \\
\text { death, } \\
\text { TVMI, } \\
\text { ID-TLR }\end{array}$ & ARC & 24 & 3 \\
\hline
\end{tabular}


Table 2 Baseline patient's and procedural characteristics

\begin{tabular}{|c|c|c|c|c|c|c|c|c|c|c|}
\hline & \multicolumn{2}{|c|}{$\begin{array}{l}\text { AIDA } \\
2017\end{array}$} & \multicolumn{2}{|c|}{$\begin{array}{l}\text { ABSORB III } \\
2017\end{array}$} & \multicolumn{2}{|c|}{$\begin{array}{l}\text { ABSORB China } \\
2016\end{array}$} & \multicolumn{2}{|c|}{$\begin{array}{l}\text { ABSORB II } \\
2016\end{array}$} & \multicolumn{2}{|c|}{$\begin{array}{l}\text { ABSORB Japan } \\
2016\end{array}$} \\
\hline & BRS & $\mathrm{EES}$ & BRS & $\mathrm{EES}$ & BRS & EES & BRS & EES & BRS & EES \\
\hline $\mathrm{N}$ of patients, $\mathrm{n}$ & 924 & 921 & 1322 & 686 & 238 & 237 & 335 & 166 & 266 & 134 \\
\hline Age, yrs. & 64 & 64 & 63 & 64 & 57 & 58 & 62 & 61 & 67 & 67 \\
\hline Male, \% & 72 & 76 & 71 & 70 & 72 & 73 & 76 & 80 & 79 & 74 \\
\hline Hypertension, \% & 51 & 50 & 85 & 85 & 59 & 60 & 69 & 72 & 78 & 80 \\
\hline Diabetes, \% & 18 & 17 & 31 & 33 & 25 & 23 & 24 & 24 & 36 & 36 \\
\hline Dyslipidaemia, \% & 38 & 38 & 86 & 86 & 42 & 38 & 75 & 80 & 82 & 82 \\
\hline Prior Ml, \% & 18 & 19 & 21 & 22 & 17 & 16 & 28 & 28 & 16 & 24 \\
\hline STEMI, \% & 25 & & 0 & & 0 & & 0 & & 0 & \\
\hline NSTEMI, \% & 20 & & 0 & & 0 & & 0 & & 0 & \\
\hline UA, \% & 8 & & 26 & & 64 & & 21 & & 12 & \\
\hline $\mathrm{SA}, \%$ & 40 & & 58 & & 19 & & 64 & & 64 & \\
\hline Silent Ischaemia, \% & NR & & 10 & & 5 & & 12 & & 23 & \\
\hline Intracoronary imaging, \% & NR & & 100 & 100 & 0.4 & 0.4 & 100 & 100 & 100 & 100 \\
\hline Pre-dilation, \% & 97 & 91 & 100 & 100 & 99.6 & 98 & 100 & 99 & 100 & 100 \\
\hline Post dilation, \% & 74 & 49.1 & 65.5 & 51.2 & 63 & 54.4 & 61 & 59 & 82.2 & 77.4 \\
\hline
\end{tabular}

yrs years, MI myocardial infarction BRS = bioresorbable vascular scaffold, EESeverolimus-eluting stent, STEMI ST-elevation myocardial infarction, NSTEMI No ST-elevation myocardial infarction; $\mathrm{UA}=$ unstable angina, $S A$ stable angina, $N R$ not reported

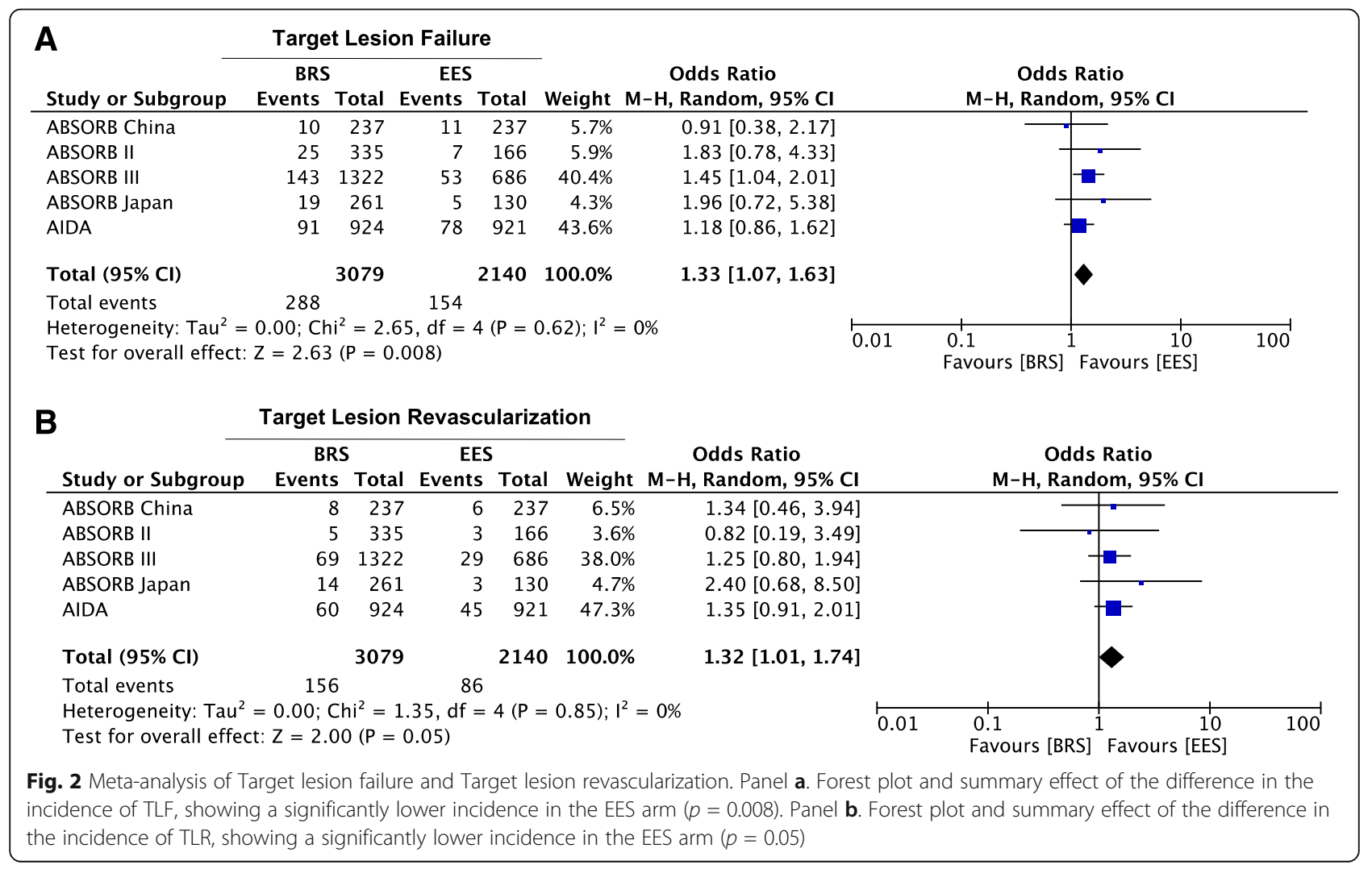




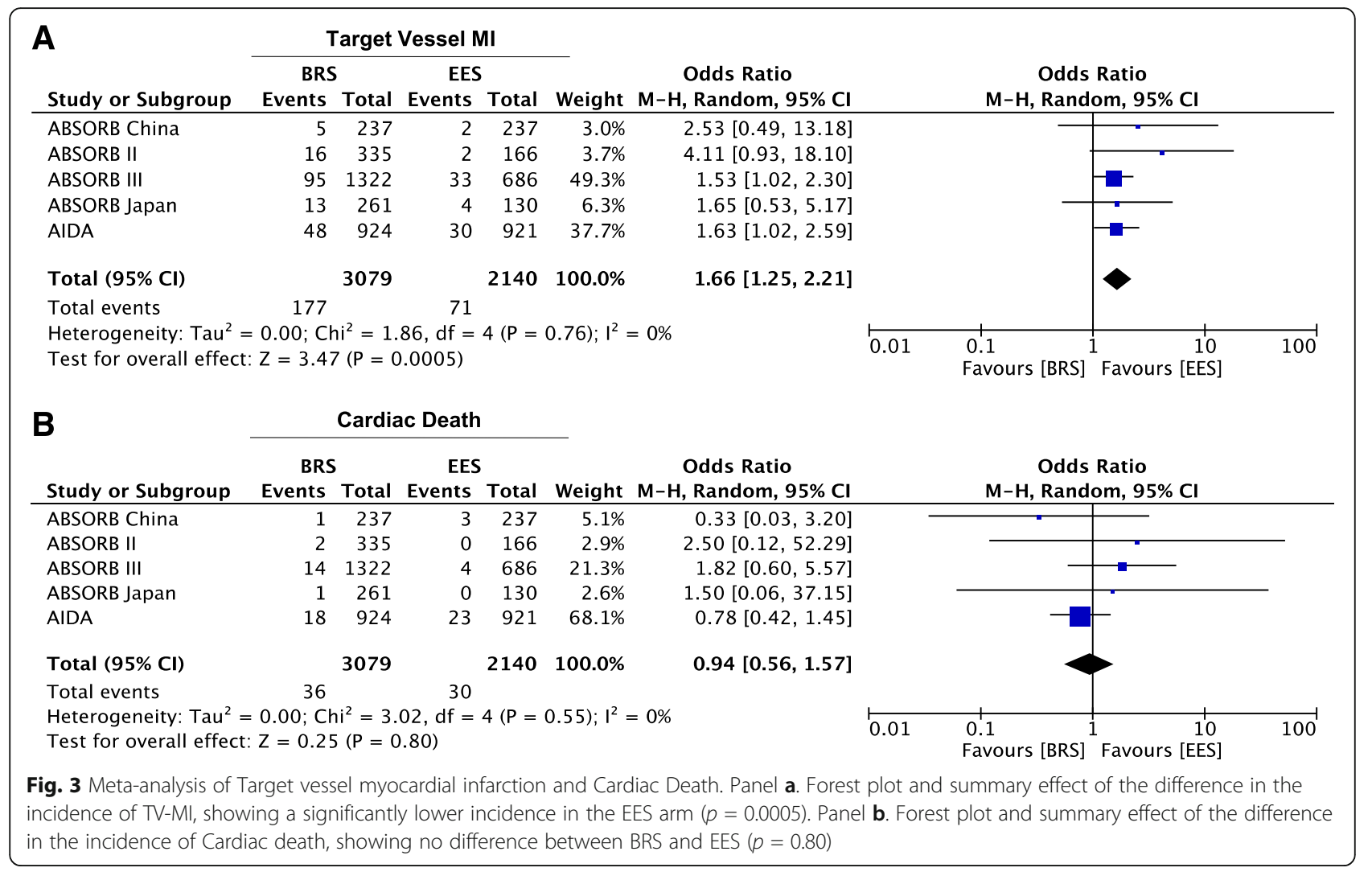

\section{Discussion}

This is the most comprehensive and updated metaanalysis of randomized studies comparing the long-term outcome after treatment of coronary artery disease with everolimus-eluting BRS or the equivalent metallic stent (EES). Summing up the best clinical evidence available to date, including 5 randomized studies and 5219 patients, we found that: a) BRS was associated with higher rates of TLF compared with EES; b) BRS was associated with higher rates of TV-MI compared with EES; c) BRS was associated with higher rates of DvT compared with EES; d) very-late DvT was higher with BRS compared with EES.
These results are not surprising, as similar trends were reported both in randomized and observational studies $[20,21]$. In particular, a previously published patientlevel meta-analysis reported a higher incidence of device thrombosis with the BRS, compared with the equivalent metallic EES [22]. However, their observation period was limited to 1 year and the studies were heterogeneous with regards to the enrollment of acute coronary syndrome and stable CAD patients [23]. Similarly, a recent published meta-analysis of RCTs and observational studies had already reported a higher risk for TLF and DvT in BRS-treated patients [24-26]. In this context, our

\begin{tabular}{|c|c|c|c|c|c|c|c|c|c|c|}
\hline \multirow{2}{*}{ Study or Subgroup } & \multicolumn{5}{|c|}{ Definite/Probable DvT } & \multirow[b]{2}{*}{$\begin{array}{c}\text { Odds Ratio } \\
\text { M-H, Random, } 95 \% \mathrm{Cl}\end{array}$} & \multirow{2}{*}{\multicolumn{3}{|c|}{$\begin{array}{c}\text { Odds Ratio } \\
\text { M-H, Random, } 95 \% \mathrm{Cl}\end{array}$}} & \\
\hline & \multicolumn{2}{|c|}{ BRS } & \multicolumn{2}{|c|}{ EES } & Weight & & & & & \\
\hline ABSORB China & 2 & 237 & 0 & 231 & $3.2 \%$ & $4.92[0.23,102.93]$ & & & & \\
\hline ABSORB II & 5 & 335 & 0 & 166 & $3.6 \%$ & $5.54[0.30,100.82]$ & & & & $\longrightarrow$ \\
\hline ABSORB III & 24 & 1322 & 5 & 686 & $32.0 \%$ & $2.52[0.96,6.63]$ & & & $\rightarrow$ & \\
\hline ABSORB Japan & 8 & 257 & 2 & 130 & $12.3 \%$ & $2.06[0.43,9.83]$ & & & $\pi$ & \\
\hline AIDA & 31 & 924 & 8 & 921 & $48.9 \%$ & $3.96[1.81,8.67]$ & & & - & \\
\hline Total $(95 \% \mathrm{Cl})$ & & 3075 & & 2134 & $100.0 \%$ & $3.22[1.86,5.57]$ & & & & \\
\hline Total events & 70 & & 15 & & & & & & & \\
\hline $\begin{array}{l}\text { Heterogeneity: } \mathrm{Tau}^{2}= \\
\text { Test for overall effect }\end{array}$ & $\begin{array}{l}=0.00 ; C h \\
: Z=4.19\end{array}$ & $\begin{array}{l}\mathrm{hi}^{2}=1.0 \\
9(\mathrm{P}<0 .\end{array}$ & $\begin{array}{l}04, \mathrm{df}= \\
.0001)\end{array}$ & $4(P=C$ & $0.90) ; I^{2}=$ & $=0 \%$ & 0.01 & $\begin{array}{l}0.1 \\
\text { Favours [BRS] }\end{array}$ & $\begin{array}{r}10 \\
\text { Favours [EES] }\end{array}$ & 100 \\
\hline
\end{tabular}




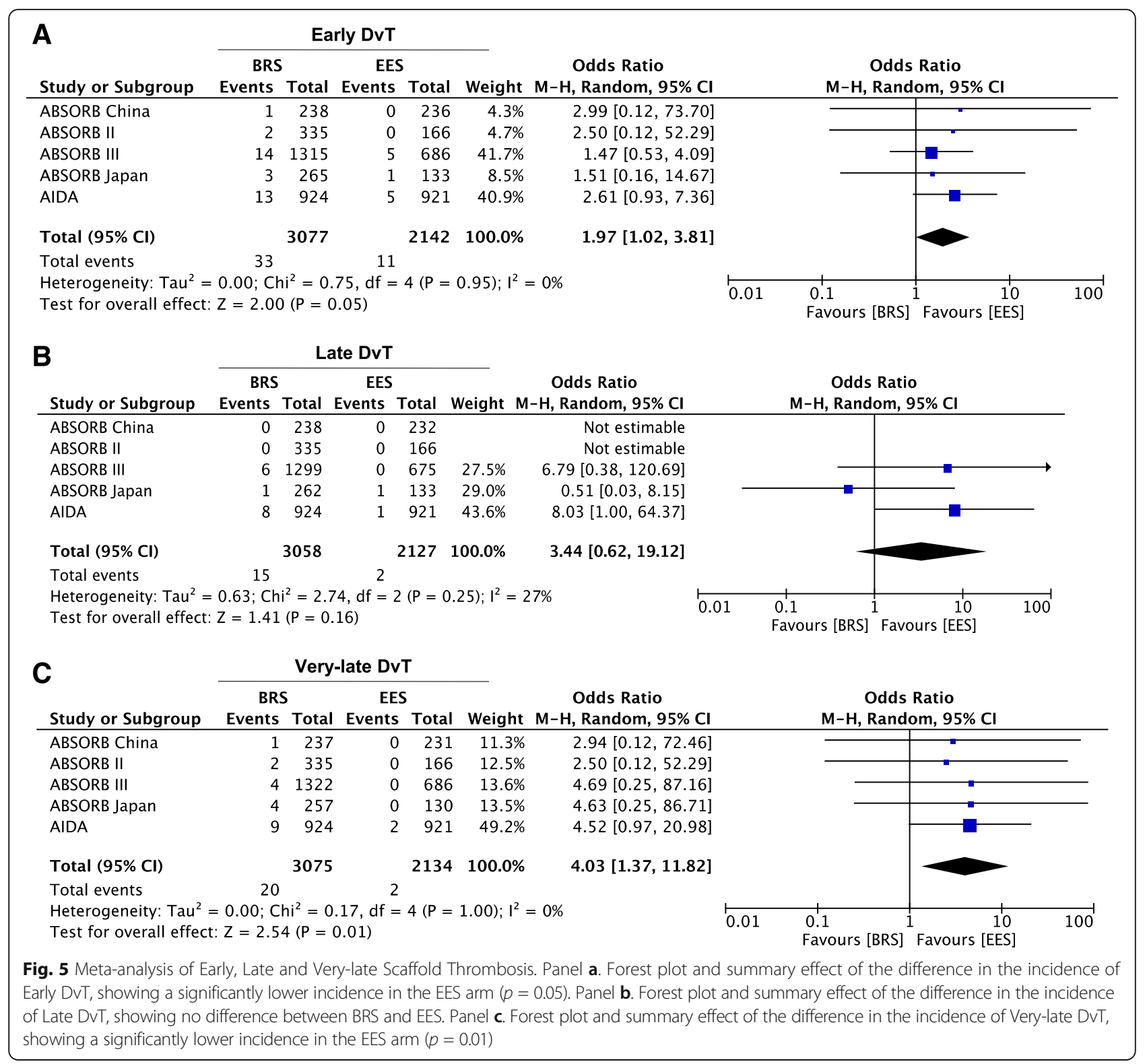

results represent a robust confirmation of the association between use of BRS and a higher rate of DvT, and are the first report of differences in DvT early, late, and very-late after implantation.

The pathophysiology of scaffold thrombosis, and the possible explanations for the increased risk as compared to drug-eluting stents (DES), and particularly the role of the implantation technique $[27,28]$ have been previously investigated. The implantation technique was not homogeneous across studies and instructions for use were not systematically followed in all studies. In fact, appropriate sizing of the balloon to be used for pre-dilation was not warranted in all patients enrolled in the Amsterdam Investigator-Initiated Absorb Strategy All-Comers Trial
(AIDA). More generally, the BRS-specific implantation protocol, prescribing long inflation times and systematic high-pressure post-dilation with a non-compliant balloon, was not homogeneously adopted in all included studies, despite it was strongly recommended to achieve optimal implantation results [29-31]. In addition, intravascular imaging guiding during BRS implantation has been reported to have a major positive impact on patients' outcome but was not frequently used across the selected studies [32-34]. Thus, a potential explanation for the observed increased risk of DvT in the randomized trials may relate to suboptimal implantation techniques, rather than to the intrinsic properties of BRS. Findings of this meta-analysis have relevant potential 
implications. The concern raised about BRS thrombosis, together with the lack of a clear advantage in terms of clinical efficacy, potentially undermines the future development of this promising class of coronary devices. In fact, the added value of the so-called vascular restoration therapy is still waiting for a proof of evidence, while interventional cardiologists have largely experienced the technical challenges in implanting the device, including worse trackability than best-in-class equivalent EES, longer procedural times, larger amounts of contrast medium necessary for successful implantation.

Collectively, the data emphasize the importance of appropriate lesion selection and accurate application of proper implantation technique. As well, a new generation of BRS should warrant a better radial strength, a sleeker endoluminal profile, a smaller footprint, and resorption processes that do not interact with the vessel wall.

\section{Study limitations}

Although no large heterogeneity was found between the randomized studies included in the present analysis, it entails possible limitations of the original studies included. There were differences in the study design, patients' and procedural characteristics. To account for these potential sources of heterogeneity, we used a random effects model for all analyses. Even though the present analysis only included high quality, randomized studies, some potential source for bias may still persist. Unfortunately, a patient level meta-analysis couldn't be possible because of lack of data. Additionally, in two of the trials, 2-year results had been presented but not have not been published yet $[15,19]$. In addition, since angina recurrence was not systematically reported in the original studies, we could not analyze the impact of BRS on this specific outcome. Moreover, we only focused on the Absorb, as this was the only type of BRS with several randomized studies and reporting long-term outcomes. Hence, our findings may not entirely apply to other BRS platforms. As well, the assessment of publication bias is limited by the small number of trials included, preventing a definitive exclusion of potential small study effect. Finally, further data on the impact of a BRS-specific implantation technique and the role of sizing on DvT are still needed, to confirm that BRS can deliver the same results as DES with the appropriate implantation techniques [35].

\section{Conclusions}

BRS may be associated with worse two-years clinical outcomes compared with EES in patients with CAD. In particular, the current data expand previous observations of an increased risk of early DvT to long-term follow-up periods.

\section{Additional files}

Additional file 1: Figure S1. Risk of bias. Summary of the study quality analysis. (PPTX $80 \mathrm{~kb}$ )

Additional file 2: Figure S2. Funnel plots. Funnel plots for $T L F, T L R$, TV-MI, Cardiac Death, Definite/Probable DVT, Early, Late and Very-late DVT, demonstrating no evidence of publication bias. Each circle represents a study. Study precision (reported on the $y$-axis as the Standard Error of the Log OR) is plotted against the summary effect. (PPTX $158 \mathrm{~kb}$ )

\begin{abstract}
Abbreviations
AIDA: Amsterdam investigator-initiated absorb strategy all-comers trial; BRS: Bioresorbable scaffolds; Cl: Confidence interval; DES: Drug eluting stent; DVT: Device thrombosis; EES: Everolimus eluting stent; ID: Ischemia-driven; MI: Myocardial infarction; OR: Odds ratio; PCl: Percutaneous coronary intervention; RCT: Randomized controlled trial; TLF: Target lesion failure; TLR: Target lesion revascularization
\end{abstract}

\section{Acknowledgements}

None.

Funding

None.

Availability of data and materials

All data generated or analysed during this study are included in this published article.

Authors' contributions

AP, SDR, and TG designed the study and acquired, analysed, and interpreted data. AP and RA did the literature search and study selection procedures. TM and $\mathrm{Cl}$ drafted the manuscript, with critical revisions for important intellectual content from all authors. All authors read and approved the final manuscript.

\section{Competing interests}

TG, TM and $\mathrm{Cl}$ have received speaker fees from Abbott Vascular. AP is a fellow of the European Association of Percutaneous Coronary Interventions. There is no other conflict with this research. Abbott Vascular had no role in any phase of this research. All other authors declare that they have no competing interests.

Consent for publication

Not applicable.

Ethics approval and consent to participate

Not applicable.

\section{Publisher's Note}

Springer Nature remains neutral with regard to jurisdictional claims in published maps and institutional affiliations.

\section{Author details \\ ${ }^{1}$ Zentrum für Kardiologie, University Hospital Mainz, Mainz, Germany. ${ }^{2}$ German Center for Cardiac and Vascular Research (DZHK), Standort Rhein-Main, Mainz, Germany. ${ }^{3}$ Division of Cardiology, Department of Medical and Surgical Sciences, "Magna Graecia" University, 88100 Catanzaro, Italy. ${ }^{4}$ URT-CNR, Department of Medicine, Consiglio Nazionale delle Ricerche of IFC, Viale Europa S/N, 88100 Catanzaro, Italy.}

Received: 18 April 2017 Accepted: 1 June 2017

Published online: 07 June 2017

\section{References}

1. Indolfi C, De Rosa S, Colombo A. Bioresorbable vascular scaffolds - basic concepts and clinical outcome. Nat Rev Cardiol. 2016;13:719-29.

2. Gori T, Münzel T. First Evidence of Complete Resorption 4 Years After Bioresorbable Scaffold Implantation in the Setting of ST-Segment Elevation Myocardial Infarction. JACC Cardiovasc Interv. 2017;10:200-2. 
3. Ormiston JA, Serruys PW. Bioabsorbable coronary stents. Circ Cardiovasc Interv. 2009;2:255-60.

4. Ormiston JA, Serruys PW, Regar E, Dudek D, Thuesen L, Webster MW, et al. A bioabsorbable everolimus-eluting coronary stent system for patients with single de-novo coronary artery lesions (ABSORB): a prospective open-label trial. Lancet. 2008:371:899-907.

5. Serruys PW, Onuma Y, Dudek D, Smits PC, Koolen J, Chevalier B, et al. J Am Coll Cardiol. 2011;58:1578-88.

6. Gori T, Schulz E, Hink U, Wenzel P, Post F, Jabs A, et al. Early outcome after implantation of Absorb bioresorbable drug-eluting scaffolds in patients with acute coronary syndromes. Eurolntervention. 2014;9:1036-41.

7. Indolfi C, Mongiardo A, Spaccarotella C, Caiazzo G, Torella D, De Rosa S. Neointimal proliferation is associated with clinical restenosis 2 years after fully bioresorbable vascular scaffold implantation. Circ Cardiovasc Imaging. 2014;7:755-7.

8. Gori T, Jansen T, Weissner M, Foin N, Wenzel P, Schulz E, et al. Coronary evaginations and peri-scaffold aneurysms following implantation of bioresorbable scaffolds: incidence, outcome, and optical coherence tomography analysis of possible mechanisms. Eur Heart J. 2016;37:2040-9.

9. Gori T, Schulz E, Hink U, Kress M, Weiers N, Weissner M, et al. Clinical, Angiographic, Functional, and Imaging Outcomes 12 Months After Implantation of Drug-Eluting Bioresorbable Vascular Scaffolds in Acute Coronary Syndromes. JACC Cardiovasc Interv. 2015;8:770-7.

10. Moher D, Liberati A, Tetzlaff J, Altman DG, PRISMA Group. Preferred reporting items for systematic reviews and meta-analyses: the PRISMA statement. BMJ. 2009:339:b2535.

11. Polimeni A, De Rosa S, Sabatino J, Sorrentino S, Indolfi C. Impact of intracoronary adenosine administration during primary PCl: A meta-analysis. Int J Cardiol. 2016;203:1032-41.

12. Polimeni A, Passafaro F, De Rosa S, Sorrentino S, Torella D, Spaccarotella C, et al. Clinical and Procedural Outcomes of 5-French versus 6-French Sheaths in Transradial Coronary Interventions. Medicine (Baltimore). 2015;94:e2170.

13. Santarpia G, De Rosa S, Polimeni A, Giampà S, Micieli M, Curcio A, et al. Efficacy and Safety of Non-Vitamin K Antagonist Oral Anticoagulants versus Vitamin K Antagonist Oral Anticoagulants in Patients Undergoing Radiofrequency Catheter Ablation of Atrial Fibrillation: A Meta-Analysis. PLoS One. 2015;10:e0126512.

14. De Rosa S, Torella D, Caiazzo G, Giampà S, Indolfi C. Left radial access for percutaneous coronary procedures: from neglected to performer? A metaanalysis of 14 studies including 7,603 procedures. Int J Cardiol. 2014;171:66-72.

15. Gao R. ABSORB China: two-year clinical results in patients with coronary artery disease randomized to the ABSORB bioresorbable vascular scaffold versus metallic drug-eluting stents. Transcatheter Cardiovascular Therapeutics. 2016; https:/www.tctmd.com/slide/absorb-china-two-year-clinical-outcomesprospective-randomized-trial-everolimus-eluting. Accessed 30 Oct 2016

16. Onuma $Y$, Sotomi $Y$, Shiomi H, Ozaki Y, Namiki A, Yasuda S, et al. Two-year clinical, angiographic, and serial optical coherence tomographic follow-up after implantation of an everolimus-eluting bioresorbable scaffold and an everolimus-eluting metallic stent: insights from the randomised ABSORB Japan trial. Eurolntervention. 2016;12:1090-101.

17. Chevalier B, Onuma Y, van Boven AJ, Piek JJ, Sabaté M, Helqvist S, et al. Randomised comparison of a bioresorbable everolimus-eluting scaffold with a metallic everolimus-eluting stent for ischaemic heart disease caused by de novo native coronary artery lesions: the 2-year clinical outcomes of the ABSORB II trial. Eurolntervention. 2016:12:1102-7.

18. Wykrzykowska JJ, Kraak RP, Hofma SH, Van der Schaaf RJ, Arkenbout EK, ljsselmuiden AJ, et al. Bioresorbable scaffolds versus metallic stents in routine PCI. N Engl J Med. doi:10.1056/NEJMoa1614954.

19. Ellis GS. Everolimus-eluting Bioresorbable Vascular Scaffolds in Patients with Coronary Artery Disease: ABSORB III Trial 2-Year Results. Am Coll Cardiol. 2017; https:/www.tctmd.com/slide/everolimus-eluting-bioresorbable-vascularscaffolds-patients-coronary-artery-disease-absorb. Accessed 19 Mar 2017

20. Kraak RP, Grundeken MJ, Hassell ME, Elias J, Koch KT, Henriques JP, et al. Two-year clinical outcomes of Absorb bioresorbable vascular scaffold implantation in complex coronary artery disease patients stratified by SYNTAX score and ABSORB II study enrolment criteria. Eurolntervention. 2016;12:e557-65.

21. Capodanno D, Gori T, Nef H, Latib A, Mehilli J, Lesiak M, et al. Percutaneous coronary intervention with everolimus-eluting bioresorbable vascular scaffolds in routine clinical practice: early and midterm outcomes from the European multicentre GHOST-EU registry. Eurolntervention. 2015;10:1144-53.

22. Stone GW, Gao R, Kimura T, Kereiakes DJ, Ellis SG, Onuma Y, et al. 1-year outcomes with the Absorb bioresorbable scaffold in patients with coronary artery disease: a patient-level, pooled meta-analysis. Lancet. 2016;387:1277-89.
23. Cassese S, Byrne RA, Ndrepepa G, Kufner S, Wiebe J, Repp J, et al. Everolimus-eluting bioresorbable vascular scaffolds versus everolimuseluting metallic stents: a meta-analysis of randomised controlled trials. Lancet. 2016;387:537-44.

24. Toyota T, Morimoto T, Shiomi H, Yoshikawa Y, Yaku H, Yamashita Y, et al. Very Late Scaffold Thrombosis of Bioresorbable Vascular Scaffold: Systematic Review and a Meta-Analysis. JACC Cardiovasc Interv. 2017;10:27-37.

25. Nairooz R, Saad M, Sardar P, Aronow WS. Two-year outcomes of bioresorbable vascular scaffold versus drug-eluting stents in coronary artery disease: a meta-analysis. Heart. 2017; doi:10.1136/heartjnl-2016-310886.

26. Ha FJ, Nerlekar N, Cameron JD, Bennett MR, Meredith IT, West NE, et al. Midterm Safety and Efficacy of ABSORB Bioresorbable Vascular Scaffold Versus Everolimus-Eluting Metallic Stent: An Updated Meta-Analysis. JACC Cardiovasc Interv. 2017;10:308-10.

27. Puricel S, Cuculi F, Weissner M, Schmermund A, Jamshidi P, Nyffenegger T, et al. Bioresorbable Coronary Scaffold Thrombosis: Multicenter Comprehensive Analysis of Clinical Presentation, Mechanisms, and Predictors. J Am Coll Cardiol. 2016;67:921-31.

28. Tanaka A, Latib A, Jabbour RJ, Mitomo S, Regazzoli D, Leone PP, et al. Bioresorbable Vascular Scaffolds and Very Late Scaffold Thrombosis: Searching an Explanation and a Solution. JACC Cardiovasc Interv. 2017;10:745-6.

29. Sorrentino S, De Rosa S, Ambrosio G, Mongiardo A, Spaccarotella C, Polimeni A, et al. The duration of balloon inflation affects the luminal diameter of coronary segments after bioresorbable vascular scaffolds deployment. BMC Cardiovasc Disord. 2015;15:169.

30. Imori Y, D'Ascenzo F, Gori T, Münzel T, Fabrizio U, Campo G, et al. Impact of postdilatation on performance of bioresorbable vascular scaffolds in patients with acute coronary syndrome compared with everolimus-eluting stents: A propensity score-matched analysis from a multicenter "real-world" registry. Cardiol J. 2016;23:374-83.

31. Biscaglia S, Ugo F, lelasi A, Secco GG, Durante A, D'Ascenzo F, et al. Bioresorbable Scaffold vs. Second Generation Drug Eluting Stent in Long Coronary Lesions requiring Overlap: A Propensity-Matched Comparison (the UNDERDOGS study). Int J Cardiol. 2016;208:40-5.

32. Biscaglia S, Secco GG, Tumscitz C, Di Mario C, Campo G. Optical coherence tomography evaluation of overlapping everolimus-eluting bioresorbable vascular scaffold implantation quided by enhanced stent visualization system. Int J Cardiol. 2015;182:1-3.

33. Biscaglia S, Campo G, Tebaldi M, Tumscitz C, Pavasini R, Fileti L, et al. Bioresorbable vascular scaffold overlap evaluation with optical coherence tomography after implantation with or without enhanced stent visualization system (WOLFIE study): a two-centre prospective comparison. Int J Cardiovasc Imaging. 2016;32:211-23.

34. Caiazzo G, Longo G, Giavarini A, Kilic ID, Fabris E, Serdoz R, et al. Optical coherence tomography guidance for percutaneous coronary intervention with bioresorbable scaffolds. Int J Cardiol. 2016;221:352-8.

35. Ielasi A, Varricchio A, Campo G, Leoncini M, Cortese B, Vicinelli P, et al. A prospective evaluation of a standardized strategy for the use of a polymeric everolimus-eluting bioresorbable scaffold in ST-segment elevation myocardial infarction: Rationale and design of the BVS STEMI STRATEGY-IT study. Catheter Cardiovasc Interv. 2016; doi:10.1002/ccd.26801.

\section{Submit your next manuscript to BioMed Central and we will help you at every step:}

- We accept pre-submission inquiries

- Our selector tool helps you to find the most relevant journal

- We provide round the clock customer support

- Convenient online submission

- Thorough peer review

- Inclusion in PubMed and all major indexing services

- Maximum visibility for your research

Submit your manuscript at www.biomedcentral.com/submit
Biomed Central 